\title{
ANALISIS BREAK EVENT POINT (BEP) PADA PT. ES MUDA PERKASA DENGAN MENGGUNAKAN METODE HARGA POKOK PRODUKSI (HPP)
}

\author{
Chairul Amni ${ }^{1}$, Indrayani ${ }^{2}$ \\ ${ }^{1}$ Universitas Serambi Mekkah, ${ }^{2}$ Universitas Malikussaleh \\ lamni_st@serambimekkah.ac.id, ${ }^{2}$ indrayani@unimal.ac.id
}

\begin{abstract}
The survival of the company or the growth of the company, one part of the planning of profit planning profit used in the company is Break Even Point (BEP), which explains the relationship between costs, production volume, selling price in order to obtain the results of the company's research. This pricing is one of the determinants of competition in the market with similar industries. PT. Es Muda Perkasa is a company engaged in the industry of making ice blocks. In the competition, PT. Es Muda Perkasa has an approved selling price sufficient to compete in the industrial world but the prices offered by PT. Mighty Ice Young is still low. This is of course difficult for companies to be able to compete because the pricing that is applied is only based on estimation, so the price determined is not in accordance with production costs. Therefore the company needs to return to how the strategy of determining the price so that it can be achieved maximally, the determination and achievement of the BEP of the company can reach within a specified time. This study aims to analyze Break Event Point (BEP) at PT. Es Muda Perkasa, by determining the optimal selling price of ice blocks. The research method used in this study uses the calculation of event break-even points using the method of calculating the cost of production. Data collection using collection of observations, interviews, and literature studies. The results of the study showed break-even (break-even point) PT. Perkasa Es Muda after selling beam products as many as 2400 blocks with a turnover obtained for BEP amounting to Rp.605,812 with a selling price of ice blocks of Rp. 18.496 / stem.
\end{abstract}

Keywords: Selling Price, Ice Block, Break Event Point (BEP)

\section{PENDAHULUAN}

Kemajuan suatu perusahaan sangat bergantung kepada sikap manajerial dalam mengelola sumber daya yang dimilikinya, serta memanfaatkan peluang yang ada, disamping itu seorang manajer juga harus memiliki kewaspadaan terhadap kemungkinan ancaman dari para pesaing yang akan merebut pangsa pasarnya, yang berakibat akan menurunkan tingkat penjualan serta berkurangnya laba yang cukup berpengaruh terhadap kelangsungan hidup atau pertumbuhan perusahaan. Salah satu bagian perencanaan laba perencanaan laba yang digunakan dalam perusahaan adalah Break Even Point (BEP). BEP dapat menggambarkan tentang hubungan antara volume produksi, harga jual, dan biaya yang ditimbulkan dalam rangka memperoleh gambaran titik impas terhadap keuangan perusahaan.

Perusahaan yang memproduksi es balok yang tumbuh belakangan ini juga mengalami peningkatan, dikarenakan permintaan masyarakat yang semakin meningkat khususnya diwilayah Kota Banda Aceh dan Aceh Besar. Oleh karena itu seiring dengan peningkatan permintaan pasar, perusahaan dituntut 
dapat memenuhi kebutuhan pasar, dalam produk es balok dengan kualitas yang baik, serta dengan perolehan produk dengan harga terjangkau, dan memperhatikan persaingan pasar. Perusahaan PT. Es Muda Perkasa dalam melakukan produksi selalu memperhatikan kualitas produk dan penentuan harga jual. Penentuan harga ini merupakan faktor dalam menentukan persaingan di pasaran dengan industri/produk yang sejenis. Penetapan harga yang dilakukan perusahaan haruslah penuh dengan kehatihatian. Sehingga harga yang ditawarkan tidak terlalu murah atau terlalu mahal tetapi tetap memberikan keuntungan yang lebih bagi perusahaan. (PT. Es Muda Perkasa, 2017)

Pertumbuhan usaha produksi es balok memberi dampak pada perkembangan/ pertumbuhan perekonomian masayarakat luas, oleh karena itu pemerintah dan pihak swasta dituntut untuk terus memproduksi barang dan jasa yang dapat menghasilkan penambahan terhadap pendapatan daerah dari pajak. Demi tercapainya kelangsungan hidup rakyat banyak, maka sangat diharapkan peran serta pihak swasta untuk dapat terus memproduksi barang. Kegiatan yang dapat dihasilkan dalam bidang usaha seperti produksi es balok yang masih memiliki permintaan yang cukup tinggi di berbagai daerah Aceh saat ini.

PT. Es Muda Perkasa merupakan salah satu perusahaan bidang industri pembuatan es balok dan es kristal padat. PT. Es Muda Perkasa hanya melakukan usaha pembuatan es balok batangan yang permintaannya banyak dari kalangan nelayan. PT. Es Muda Perkasa menawarkan harga jual yang bisa bersaing dengan usaha lainnya. Hal tersebut tentu tidak optimal untuk perusahaan karena penetapan harga hanya berdasarkan perkiraan saja, sehingga harga yang ditawarkan tidak sejalan dengan biaya produksi yang dikeluarkan. Perusahaan perlu meninjau kembali cara strategi penentuan harga agar keuntungan yang didapat bisa secara maksimal sehingga penetapan dan pencapaian BEP perusahaan bisa dicapai dalam waktu yang sudah ditentukan.

Berdasarkan uraian latar belakang diatas, maka rumusan masalah penelitian adalah bagaimanakah metode perhitungan BEP pada PT. Es Muda Perkasa, dengan penentuan harga jual es balok yang lebih optimal agar pencapaian keuntungan sesuai dengan biaya produksi yang sudah dikeluarkan.

Adapun tujuan dari penelitian adalah untuk menganalisis Break Event Point (BEP) pada PT. Es Muda Perkasa, dengan penentuan harga jual es balok yang lebih maksimal.

\section{METODE PENELITIAN}

Untuk memperoleh data primer sebagai data utama dalam penulisan proposal ini, penulis melakukan penelitian ini pada PT. Es Muda Perkasa yang berada di Desa Ajun, Kecamatan Peukan Bada, Kabupaten. Aceh Besar. Peneliti melakukan beberapa pendekatan pengumpulan data sebagai berikut:

1. Pengamatan dan penelitian langsung terhadap objek penelitian (observasi)

2. Wawancara kepada pihak-pihak yang dapat memberikan informasi yang berkenaan dengan penyelesaian / pembahasan masalah.

3. Studi kepustakaan untuk mempelajari konsepkonsep yang memiliki kaitan dengan permasalahan untuk analisa dan evaluasi terhadap hasil penelitian.

Setelah dilakukan pengumpulan data, selanjutnya pemilahan data sesuai sumber data yang terbagi dari data primer dan data sekunder sebagai informasi yang akan dikemas dalam karya tulis ini yang menjadi satu kesatuan. 
Volume 8, Nomor 1, Februari, 2020

1. Data Pimer

Peneliti langsung terhadap analisa biaya mengambil objek penelitian pada PT. Es Muda Perkasa.

2. Data Sekunder

Data skunder diperlukan data yang diambil dari teori-teori dengan melakukan penelitian kepustakaan.

Pengolahan data hasil penelitian dengan langkah-langkah sebagai berikut:

\section{Perhitungan Harga Pokok Produk (HPP)}

Perhitungan Break Event Point (BEP) merupakan perhitungan pada setiap komponen biaya yang dikeluarkan pada saat proses produksi, salah satu metode perhitungan menggunakan metode perhitungan Harga Pokok Produksi (HPP), dengan menggunakan analisa titik impas, dengan analisa bahwa perusahaan tidak memperoleh keuntungan dan tidak mengalami kekurangan atas modal yang telah dikeluarkan. Perhitungan harga pokok produk ini meliputi biaya-biaya yaitu biaya tetap dan biaya variabel. Persamaan untuk melakukan HPP adalah sebagai berikut:

$$
\mathrm{HHY}=\frac{\text { biaya variabel }+ \text { biaya teta }}{\text { jumlah produksi }} \ldots .
$$

\section{Perhitungan Target Profit Pricing}

Menurut Alma dan Hurriyati, (2008), bahwa harga/uang merupakan alat tukar untuk memperoleh produk atau jasa yang dikeluarkan konsumen kepada produsen, diantaranya elemen bauran pemasaran yang lain harga itu merupakan satu-satunya elemen yang menghasilkan biaya. Harga/uang merupakan satusatunya elemen dari bauran pemasaran yang paling fleksibel. Setelah harga pokok produk didapat maka dilakukan perhitungan harga jual produk dengan rasio persentase keuntungan yang diinginkan. Persamaan untuk perhitungan tersebut sebagai berikut:

$$
\text { Harga Jual }=\frac{\text { harga pokok }}{(1-\% \text { laba })}
$$

\section{Perhitungan Break Even Point}

Menurut Djarwanto, dan Subagyo (2002) titik impas merupakan keadaan jumlah pendapatan dan biaya dengan kondisi seimbang sehingga tidak terdapat keuntungan ataupun kerugian. Persamaan perhitungan titik impas sebagai berikut:

$$
B E F=\frac{\text { biaya terap }}{\text { harga jual }- \text { b.variabel }}
$$

\section{Tahapan Penelitian}

Untuk mengetahui tahapan-tahapan penelitian pada PT. Es Muda Perkasa, maka dapat dilihat pada gambar 1:

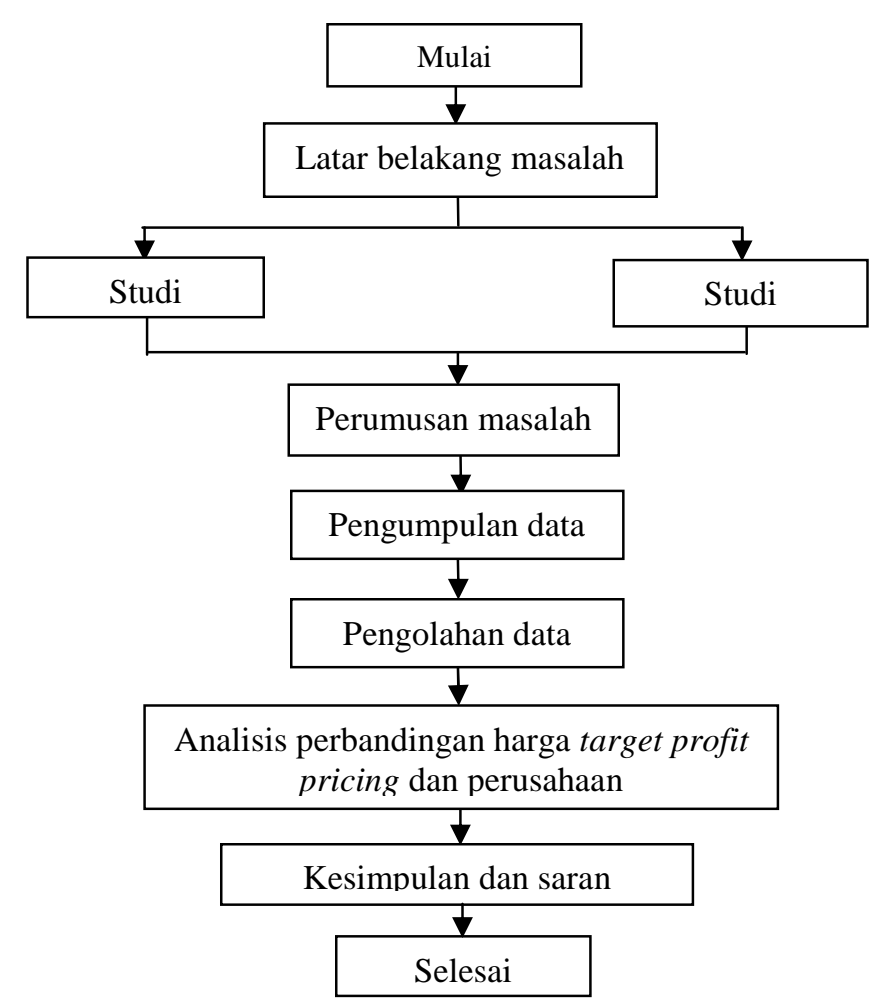

Gambar 1. Tahapan Penelitian Pada PT. Es Muda Perkasa 


\section{PEMBAHASAN}

\section{Sejarah Singkat Berdirinya PT. Es Muda Perkasa}

PT. Es Muda Perkasa adalah perusahaan yang bergerak dibidang usaha es balok dan es kristal, dengan proses pengubahan liquid/cairan menjadi benda padat (es) dalam bentuk es balok. Proses pembuatan es dengan cara membekukan benda cair, kegiatan keseluruhan fungsi yang ada di perusahaan untuk melaksanakan rencana usaha sehingga dapat terus beroperasi dan berkembang hingga saat ini.

PT. Es Muda Perkasa memproduksi es balok sekitar 2400 balok/bulan atau sebanyak 80 batang/hari. Proses produksi memakan waktu 1-2 jam pada setiap satu kali proses hingga bisa di pasarkan. (PT. Es Muda Perkasa.2018)

Harga produksi yang di tawarkan berdsasarkan standar harga pada umumnya, yaitu Rp.18.000/batang, PT. Es Muda Perkasa dalam menjalankan fungsinya mempunyai tugas pokok menghasilkan Es balok yang berkualitas, dapat diterima konsumen, dan mempermudah konsumen dalam memperoleh es balok.

Air bersih merupakan bahan baku utama PT. Es Muda Perkasa yang bersumber dari PDAM Tirta Daroy Kota Banda Aceh. Gas amonia merupakan bahan baku tambahan yang digunakan selain air bersih. Penggunaan gas amoniak sebagai bahan es balok dapat berfungsi dan menghasilkan es yang sesuai dengan kualitas yang diharapkan, disamping itu diperlukan komponen yang mendukung kegiatan produksi. komponen-komponen terdiri dari material bahan baku, mesin atau peralatan dan juga karyawan yang mengolahnya. Komponen-komponen yang diperlukan dalam produksi es balok, yaitu:

Tabel 1. Bahan baku PT. Es Muda Perkasa

\begin{tabular}{|c|c|c|}
\hline Air & Es Balok & PDAM \\
\hline Gas Amonia & Refrigerant & Kontraktor Pabrik \\
\hline Solar & Mobil Truck Box & Pertamina \\
\hline Solar & Ginset & Pertamina \\
\hline
\end{tabular}

Sumber:PT. Es Muda Perkasa

\section{Proses Produksi Es Balok}

Proses produksi diawali dari pengambilan bahan baku berupa air bersih, tidak berbau dan tidak berwarna, dengan $\mathrm{pH}$ air sebesar 7. Bahan baku PT. Es Muda Perkasa merupakan air bersih yang bersumber dari PDAM dan dialirkan ke dalam water tank sebagai persediaan bahan baku, kemudian dialirkan ke dalam bak penampung.

Selain sebagai tempat persediaan fungsi bak penampung juga digunakan sebagai media pengendapan kotoran yang terbawa oleh bahan baku, sehingga kotoran tidak ikut terproses. Pengendapan air dilakukan selama 2 hari sebelum akhirnya digunakan sebagai bahan baku produksi. Bahan baku yang tersedia pada water tank dialirkan ke dalam fill tank, adapun fungsi dari fill tank sebagai tempat penampung bahan baku yang telah siap digunakan. Proses produksi es balok pada PT. Es Muda Perkasa dapat diuraikan sebagai berikut :

1 Tahap I (Proses Pengisian Ice can)

Cetakan es (Ice can) diisi dengan air murni dengan menggunakan Filling Tank (Tangki Pengisian Air) sebagai bahan utama produksi es. Ice can yang dipakai terbuat dari plat $1.8 \mathrm{~mm}$ dengan lapisan anti karat (galvanis), dan dilengkapi dengan frame isi 20 unit cetakan, masing-masing cetakan mempunyai berat $60 \mathrm{~kg}$. Filling Tank (Tangki pengisisan air) dilengkapi dengan katup dan level control sehingga dapat sesuaikan dengan kapasitas tangki.

2 Tahap II (Proses Pengangkatan)

\begin{tabular}{|l|l|l} 
Bahan Baku & Keperluan & Sumber
\end{tabular}


Volume 8, Nomor 1, Februari, 2020

Proses pengangkatan dilakukan setelah pengisian selesai, ice can kemudian diangkat dan diletakkan kedalam bak pendingin (Brine Tank) yaitu dengan memasang ice can pada rei (alat bantu untuk proses penempatan) yang terdapat pada bagian atas Brine Tank.

3 Tahan III (Proses Pendinginan)

Proses pendinginan dilakukan terhadap Ice can kemudian dicelupkan ke dalam Brine Tank dan terendam sampai level air di dalam ice can sejajar dengan level brine tank (tangki proses). Brine berfungsi sebagai pendingin (refrigerant) berfungsi untuk memindahkan kalor sehingga air menjadi dingin dan lama-kelamaan akan membeku (menjadi es). Proses pendinginan yang diperlukan kurang lebih 24 jam agar es balok yang dihasilkan nantinya benar-benar matang. Pada proses Brine Tank dilengkapi alat pengaduk air garam (brine agitator) agar larutan garam yang dihasilkan lebih merata dan brine sehingga tidak menjadi gel/bubur dikarenakan temperatur suhu terlalu dingin.

4 Tahap IV (Proses Perendaman)

Proses perendaman es balok apabila sudah terbentuk (membeku), maka proses selanjutnya adalah pengangkatan ice can dari brine tank dan dilakukan perendaman di air normal pada Dip Tank (tangki pelepas es), yang bertujuan agar sisi es balok terluar mencair, sehingga es balok tersebut mudah terlepas dari ice can.

\section{Tahap VI (Proses Pelepasan)}

Proses pelepasan setelah sisi es balok mencair, kemudian es diangkat dari ice can dengan menggunakan rei, setelah es balok keluar maka diangkut kebagian penyortiran dengan mengunakan peluncur es (can dumper).

\section{Tahap VI (Proses Penyortiran)}

Es balok yang sudah terlepas dari ice scan kemudian disortir untuk memperoleh es balok yang memiliki kriteria layak untuk dijual ke konsumen.

Hasil produksi es balok yang dihasilkan ratarata memiliki berat $60 \mathrm{~kg}$ perbatang. Dengan kapasitas produksi es balok sebanyak 2000 lebih es balok setiap hari. Angka ini berdasarkan kapasitas mesin produksi yang berkapasitas 120 ton.

Secara teknis, jika seluruh komponen yang di jalankan tidak sesuai seperti aturan yang telah ditentukan (salah perhitungan), proses produksi es tidak akan trcapati dengan maksimal, bahkan bisa memerlukan waktu yang lama sehingga tidak efesien, oleh karena itu; penentuan kerja, perhitungan dan pemeriksaan spesifikasi teknis dari komponenkomponen tersebut menjadi sangat penting. Sehingga bisa mendongkrak nilai jual produk.

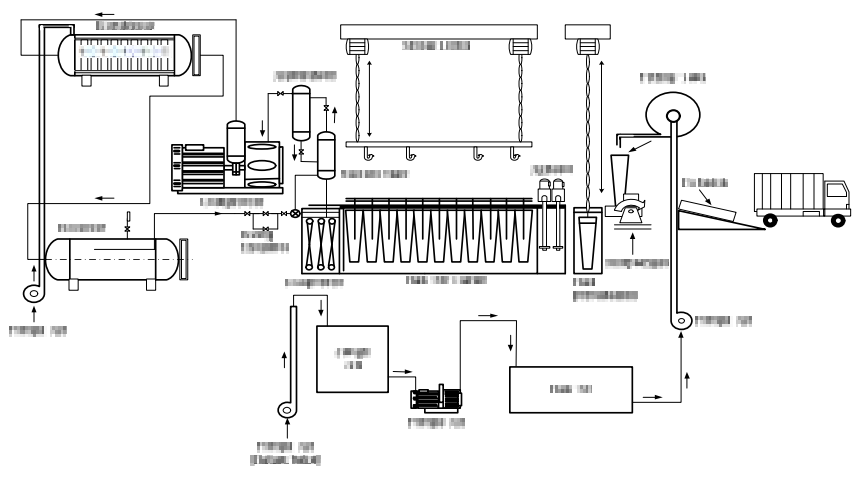

Gambar 2. Diagram Alur Proses

\section{Analisis Biaya PT. Es Muda Perkasa}

Analisis biaya ini akan dibutuhkan dalam penetapan harga penjualan produk seperti biaya variabel dan biaya tetap yang dikeluarkan PT. Es Muda Perkasa selama proses produksinya. 


\section{Biaya Variabel}

Biaya variabel akan menampilkan komponen biaya yang berpengaruh pada penetapan harga, diantaranya data biaya bahan baku dan biaya overhead variable produksi. Ada 3 bahan baku yang diperlukan pada proses pembuatan batu bata, antara lain yaitu:

1. Air

2. Garam

3. Amoniak

Berikut hasil data harga dan pengunaan bahan baku yang didapat dari PT. Es Muda Perkasa pada tabel 3 berikut:

Tabel 3. Data Jumlah Bahan Baku dan Total Harga

Bahan Baku/bulan

\begin{tabular}{|c|c|c|c|c|}
\hline No & $\begin{array}{c}\text { Bahan } \\
\text { Baku }\end{array}$ & Jumlah & $\begin{array}{c}\text { Harga } \\
\text { satuan } \\
(\mathrm{Rp})\end{array}$ & $\begin{array}{c}\text { Total biaya } \\
\text { (Rp) }\end{array}$ \\
\hline 1. & Air & $\begin{array}{c}10 \\
\text { kubik }\end{array}$ & & 10.000 .000 \\
\hline 2 & Garam & 3 ton & $\begin{array}{c}3500 / \\
\mathrm{kg}\end{array}$ & 1.500 .000 \\
\hline 3 & Armoniak & $80 \mathrm{~kg}$ & 13000 & 1.400 .000 \\
\hline \multicolumn{4}{|c|}{ Total } & 12.900 .000 \\
\hline
\end{tabular}

Sumber:PT. Es Muda Perkasa 2018

Biaya overhead variabel ini terdiri dari biaya bahan baku, biaya penggunaan kayu bakar, dan pemakaian listrik. Berikut hasil data biaya overhead variabel pada tabel 4 berikut:

Tabel 4. Biaya Overhead Variabel

\begin{tabular}{|c|l|r|}
\hline No & \multicolumn{1}{|c|}{ Item kegiatan } & \multicolumn{1}{|c|}{$\begin{array}{c}\text { Biaya } \\
\text { Variabelbulan } \\
\text { oktober (Rp) }\end{array}$} \\
\hline 1. & $\begin{array}{l}\text { Penggunanaan bahan } \\
\text { bakar }\end{array}$ & 2000.000 \\
\hline 2. & Penggunaan listrik & 25000.000 \\
\hline \multicolumn{2}{|r|}{ Total } & 2.7000 .000 \\
\hline
\end{tabular}

Sumber :PT. Es Muda Perkasa 2018
Hasil rekapitulasi untuk biaya variabel yang terdiri dari biaya bahan baku dan biaya overhead produksi pada tabel 5 berikut:

Tabel 5. Rekapitulasi Total Biaya Variabel

\begin{tabular}{|c|l|c|}
\hline No & \multicolumn{1}{|c|}{ Jenis biaya } & $\begin{array}{c}\text { Jumlah biaya } \\
(\mathrm{Rp})\end{array}$ \\
\hline 1. & Bahan baku & 12.900 .000 \\
\hline 2 & Overhead & 27.000 .000 \\
\hline \multicolumn{2}{|c|}{ Total } & 39.900 .000 \\
\hline
\end{tabular}

Sumber :PT. Es Muda Perkasa 2018

Berdasarkan tabel di atas, dapat dijelaskan bahwa total biaya bahan baku sebesar Rp. 12.900.000, sedangakna biaya overhead pabrik adalah sebesar Rp. 27.000.000,-

\section{Biaya Tetap}

Pada biaya tetap selama produksi akan menampilkan komponen biaya yang berpengaruh pada penetapan harga diantaranya biaya pekerja langsung, biaya overhead tetap, dan biaya tetap lainnya.

\section{a. Biaya Pekerja Langsung}

Dalam setiap proses produksi diperlukan pekerja langsung, pekerja langsung adalah dimana pekerja yang langsung bekerja pada tempat proses produksi berlangsung. Berikut hasil data untuk biaya pekerja langsung pada tabel 6 berikut:

Tabel 6. Rekapitulasi Biaya Pekerja Langsung

\begin{tabular}{|c|l|l|c|}
\hline No & \multicolumn{1}{|c|}{ Kegiatan } & Jumlah & $\begin{array}{c}\text { Total } \\
\text { biayabulan } \\
\text { Oktober (Rp) }\end{array}$ \\
\hline 1 & $\begin{array}{l}\text { Melakukan } \\
\text { produksi es hingga } \\
\text { selesai proses } \\
\text { produksinya. }\end{array}$ & 14orang & 28.000 .000 \\
\hline \multicolumn{2}{|c|}{ Total } & 28.000 .000 \\
\hline
\end{tabular}

Sumber:PT. Es Muda Perkasa 2018

Tabel 7 Biaya Perawatan

\begin{tabular}{|l|l|l|l|l|}
\hline $\mathrm{N}$ & Item & Jenis & frekuens & Total \\
\hline
\end{tabular}


Volume 8, Nomor 1, Februari, 2020

\begin{tabular}{|c|l|l|c|c|}
\hline o & & $\begin{array}{c}\text { perawata } \\
\mathrm{n}\end{array}$ & $\mathrm{i}$ & $\begin{array}{c}\text { biayabulan } \\
\text { oktober(Rp } \\
\text { ) }\end{array}$ \\
\hline 1. & $\begin{array}{l}\text { Mobil } \\
\text { panther }\end{array}$ & $\begin{array}{l}\text { Service } \\
\text { rutin }\end{array}$ & 1 kali & 5.000 .000 \\
\hline 2. & $\begin{array}{l}\text { Mesin } \\
\text { Compres } \\
\text { ol }\end{array}$ & $\begin{array}{l}\text { Service } \\
\text { rutin }\end{array}$ & 1 kali & 20.000 .000 \\
\hline \multicolumn{4}{|c|}{ Total } & 25.000 .000 \\
\hline
\end{tabular}

Sumber:PT. Es Muda Perkasa 2018

b. Biaya Alat Bantu

Alat bantu sangat dibutuhkan untuk dapat menunjang jalannya proses produksi agar tidak terjadi keterlambatan produksi. Hasil untuk biaya alat bantu lihat pada tabel 8 berikut:

Tabel 8. Biaya Alat Bantu

\begin{tabular}{|c|c|c|c|c|c|c|}
\hline $\begin{array}{l}\mathrm{N} \\
\mathrm{o}\end{array}$ & Item & $\operatorname{Jmlh}$ & $\begin{array}{l}\text { Harga } \\
(\mathrm{Rp})\end{array}$ & $\begin{array}{l}\text { Total } \\
\text { biaya } \\
\mathrm{Rp})\end{array}$ & \begin{tabular}{|c|} 
Depre \\
- \\
siasi \\
(Rp)
\end{tabular} & \begin{tabular}{|c} 
Depresi \\
asi \\
bulan \\
(Rp)
\end{tabular} \\
\hline 1 & $\begin{array}{l}\text { Pomp } \\
\text { a air }\end{array}$ & $1 \mathrm{bh}$ & 400.000 & 400.000 & \begin{tabular}{r|}
200.00 \\
0
\end{tabular} & \\
\hline 2 & Derek & $2 \mathrm{bh}$ & $\begin{array}{r}5000.00 \\
0\end{array}$ & $\begin{array}{r}10.000 .0 \\
00\end{array}$ & \begin{tabular}{|r|}
5000.0 \\
00
\end{tabular} & $\begin{array}{r}416.666 \\
67\end{array}$ \\
\hline \multicolumn{7}{|c|}{ Total } \\
\hline \multicolumn{7}{|c|}{ Sumber:PT. Es Muda Perkasa 2018} \\
\hline No & \multicolumn{3}{|c|}{ Item kegiatan } & \multicolumn{3}{|c|}{ Biaya overhead (Rp) } \\
\hline 1. & \multicolumn{3}{|c|}{ Biaya perawatan } & \multicolumn{3}{|c|}{25.000 .000} \\
\hline 2. & \multicolumn{3}{|c|}{ Biaya alat bantu } & \multicolumn{3}{|c|}{850.000} \\
\hline \multicolumn{4}{|c|}{ Total } & \multicolumn{3}{|c|}{25850.000} \\
\hline
\end{tabular}

Sumber :PT. Es Muda Perkasa 2018

c. Biaya Tetap Lain
Biaya tetap lain merupakan biaya secara rutin dikeluarkan perusahaan dalam setiap bulannya diantaranya gaji pekerja tidak langsung, depresiasi kendaraan, biaya pajak kendaraan, dan biaya administrasi dan pemasaran.

1) Gaji pekerja tidak langsung

Pekerja tidak langsung merupakan pekerja yang bekerja diluar pekerja langsung. Berikut data gaji pekerja tidak langsung bisa diketahui melalui tabel 10 berikut:

Tabel 10. Biaya Pekerja Tidak Langsung

\begin{tabular}{|l|c|r|r|}
\hline Jabatan & $\begin{array}{c}\text { Kebutuhan } \\
\text { orang }\end{array}$ & $\begin{array}{c}\text { Gaji bulan } \\
(\mathrm{Rp})\end{array}$ & $\begin{array}{c}\text { Total biaya } \\
(\mathrm{Rp})\end{array}$ \\
\hline Supir & 1 orang & 1.200 .000 & 1.200 .000 \\
\hline Kenek & 1 orang & 720.000 & 720.000 \\
\hline \multicolumn{3}{|c|}{ Total } & 1.920 .000 \\
\hline
\end{tabular}

Sumber:PT. Es Muda Perkasa 2018

depresiasi

(RP)

16.686.6Depresiasi Kendaraan

$7 \quad 7$ Jenis kendaraan yang dimiliki PT. Es Muda 3asa adalah mobil panther tahun 2000 yang dibeli den harga beli. Rp. 60.000.000, umur pakai 10 85.00 dengan depresiasi kendaraan perbulan sebesar Rp. 250.000.

\section{3) Depresiasi Mesin}

Jenis mesin yang dimiliki PT. Es Muda Perkasa adalah mesin compresol tahun 2012 yang dibeli dengan harga beli. Rp. 12.000.000, umur pakai 10 tahun dengan depresiasi mesin perbulan sebesar Rp. 50.000 .

\section{4) Biaya Pajak Kendaraan}

Biaya pajak kendaraan termasuk dalam biaya tetap yang harus dikeluarkan oleh perusahaan tiap tahunnya. Biaya pajak yang dikeluarkan oleh perusahaan sebesar Rp. 1.000.000/tahun, atau Rp. 
$1.000 .000 / 12$ bulan $=83.333,33$ setiap bulan selama 12 bulan.

5) Biaya Administrasi dan Pemasaran

Selain biaya produksi, terdapat biaya yang juga bias mempengaruhi harga pokok produk yang dihasilkan. Berikut hasil data biaya administrasi dan pemasaran dapat dilihat pada tabel 11 berikut:

Tabel 11 Biaya Administrasi dan Pemasaran

\begin{tabular}{|c|l|r|}
\hline No & \multicolumn{1}{|c|}{ Item kegiatan } & \multicolumn{1}{|c|}{$\begin{array}{c}\text { Total biaya } \\
\text { bulan Oktober } \\
\text { (Rp) }\end{array}$} \\
\hline 1. & Telepon & 1.000 .000 \\
\hline 2. & Alat tulis kantor & 50.000 \\
\hline 3. & Keperluan air minum (12 galon) & 36.000 \\
\hline \multicolumn{2}{|r|}{ Total } & 1086000 \\
\hline
\end{tabular}

Sumber :PT. Es Muda Perkasa 2018

Total biaya tetap mencakup jumlah dari biaya overhead tetap dan biaya tetap lain. Rekapitulasi untuk total biaya overhead tetap bisa diketahui melalui tabel 12 berikut:

Tabel 12. Rekapitulasi Total Biaya Tetap

\begin{tabular}{|c|l|r|}
\hline No & \multicolumn{1}{|c|}{ Jenis biaya } & \multicolumn{1}{c|}{ Jumlah biaya } \\
\hline 1. & Pekerja langsung & 28.000 .000 \\
\hline 2. & Overhead tetap & 1.920 .000 \\
\hline 3. & $\begin{array}{l}\text { Biaya pekerja tidak } \\
\text { langsung }\end{array}$ & 1086000 \\
\hline 4. & $\begin{array}{l}\text { Administrasi dan } \\
\text { pemasaran }\end{array}$ & $83.333,33$ \\
\hline 5. & Pajak kendaraan & 250.000 \\
\hline 6. & Depresiasi mobil panther & 50.000 \\
\hline 7. & $\begin{array}{l}\text { Depresiasi mesin } \\
\text { compresol }\end{array}$ & $66.639,333$ \\
\hline \multicolumn{2}{|c|}{ Total } \\
\hline
\end{tabular}

Sumber :PT. Es Muda Perkasa 2018
Tabel 13. Rekapitulasi Total Biaya Tetap dan Biaya Variabel

\begin{tabular}{|c|l|r|}
\hline No & \multicolumn{1}{|c|}{ Jenis biaya } & \multicolumn{1}{c|}{ Total Biaya (Rp) } \\
\hline 1. & Biaya tetap & 66.639333 \\
\hline 2 & Biaya variable & 12.900 .000 \\
\hline \multicolumn{2}{|c|}{ Total } & 79.539 .333 \\
\hline
\end{tabular}

Sumber:PT. Es Muda Perkasa 2018

\section{Perhitungan Break Even Point}

Pada perhitungan harga jual ini adalah proyeksi terhadap harga jual produk es balok dan perhitungan harga pokok.

1. Perhitungan Harga Pokok Produk

Pada metode perhitungan laba menggunakan perhitungan titik balik modal, yang mana konidisi perusahaan tidak memperoleh keuntungan dan kerugian terhadap modal yang telah dikeluarkan selama produksi. Perhitungan biaya pokok produk meliputi biaya-biaya yaitu biaya tetap dan biaya variabel. Rumus untuk melakukan perhitungan harga pokok produk (HPP) adalah sebagai berikut:

$\mathrm{HPH}=\frac{\text { biayavariabel }+ \text { biayatetap }}{\text { jumlah produksi }}$

$\mathrm{HPP}=\frac{59.900 .000+00.059,553}{2400}$

$\mathrm{HPP}=\frac{44391,589}{2400}$

\section{$\mathrm{HHY}=\mathrm{Rp} .18,490 /$ batang}

\section{Perhitungan Target Profit Pricing}

Perhitungan target profit pricing di peroleh setelah analisa harga pokok produksi dengan melakukan perhitungan terhadap harga jual produk bersama persentase keuntungan yang diinginkan. Perhitungan harga jual dengan keuntungan 10\% 
Volume 8, Nomor 1, Februari, 2020

dengan menggunakan metode persamaan sebagai

berikut:

Harga Jual $=\frac{\text { harga polcok }}{(1-\% ! a b a)}$

Harga Jual $=\frac{18,490412}{(1-10 \%)}$

Harga Jual $=\frac{18,490412}{0,9}$

Harga Jual $=$ Kp. 20,551/batang

Perhitungan harga jual dengan keuntungan 15\% menggunakan metode Target Profit Pricing dengan rumus sebagai berikut:

Harga Jual $=\frac{\text { harga polkok }}{(1-\% l a b a)}$

Harga Jual $=\frac{18,490412}{(1-15 \%)}$

Harga Jual $=\frac{18,496412}{0,85}$

Harga Jual $=\mathrm{Kp} \cdot 21,100 /$ batang

Perhitungan harga jual dengan keuntungan 20\% menggunakan metode Target Profit Pricing dengan rumus sebagai berikut:

Harga Jual $=\frac{\text { harga pokok }}{(1-\% \text { laba })}$

Harga Jual $=\frac{18,490412}{(1-20 \%)}$

Harga Jual $=\frac{18,490412}{0,8}$

Harga Jual $=$ Rp. 23,120/batang

\section{Perhitungan Break Even Point}

Perhitungan titik impas perusahaan merupakan kondisi pendapatan dan biaya yang telha dikeluarkan oleh perusahaan yaitu sama atau seimbang sehingga tidak mendapat keuntungan atau kerugian.

BEP merupakan analisis terhadap proyeksi banyaknya jumlah unit yang diproduksi atau sebanyak apa uang yang harus diterima untuk mendapatkan titik impas atau balik modal. Dengan melakukan perkiraan titik impas, maka perusahaan dapat mengetahui pengembalian modal dari hasil penjualan dengan pengeluaran. Persamaan terhadap analisa titik impas sebagai berikut:

1. BEP Unit: titik pulang pokok yang dinyatakan dalam jumlah penjualan produk di nilai tertentu.

2. BEP Rupiah: titik pulang pokok yang dinyatakan dalam jumlah penjualan atau harga penjualan produk tertentu.

Rumus /cara menghitung BEP:

BEP Unit $=\frac{\text { biaya tecap }}{\text { harga perunit }- \text { biayavariabel }}$

BEY Rupiah $=\frac{\text { biaya tetap }}{\text { kontribusi małgin perunit } / \text { hargaperunit }}$

Dari data biaya tetap dan biaya variabel, maka selanjutnya kita dapat meghitung BEP (break evet point) dalam unit dan rupiah sebagai berikut:

Dengan persamaa $\mathbf{Y}=\mathbf{c x}-\mathbf{b x} \mathbf{-} \mathbf{a}$, BEP tercapai bila $\mathbf{Y}$ $=\mathbf{0}$, maka dalam hal ini adalah:

c= Rp. 18,496412/batang

$\mathbf{x}=2400$ batang

$\mathbf{a}=\operatorname{Rp} .66 .639,333$

bx $=$ Rp. 39.900 .000 


$$
\begin{aligned}
& b=\frac{b x}{x} \\
& b=\frac{59, y u v, v u v}{2400}=16,625 \\
& \text { selanjutnya, } \\
& \text { BEF Unit }=\frac{u}{(c-b)} \\
& \text { BEF Unit }=\frac{00,059,553}{(18,490412-16,625)} \\
& =\frac{60,639,333}{18,4 / 9,787} \\
& =2400 \text { batang }
\end{aligned}
$$

Dalam rupiah dapat dihitung sebagai berikut:

$$
\begin{aligned}
\text { BEF Rupiah } & =\frac{u}{1-\frac{b}{c}} \\
\text { BEF Kupiah } & =\frac{00,039,333}{1-\frac{10,625}{18,496412}} \\
& =\frac{60,639,333}{1-0,89} \\
& =\frac{00,039,333}{0,11} \\
& =\operatorname{Rp}, 605,812
\end{aligned}
$$

Untuk lebih jelas kapan titik break even point (BEP) pada PT. Es Muda Perkasa maka dapat dilihat pada gambar 3 berikut:

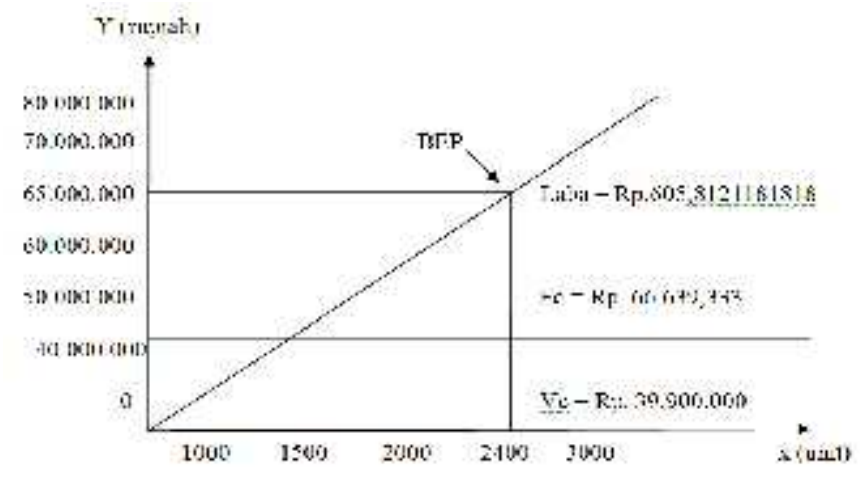

Gambar 3. Grafik Break Even Point

Dari hasil analisis break even point di atas bisa kita lihat untuk mendapatkan titik impas (break even point) maka PT. Es Muda Perkasa harus menjual produk es balok sebesar 2400 batang es balok dengan omzet yang harus diperoleh untuk BEP adalah sebesar Rp.605,812 dengan harga jual es balok sebesar Rp. 18,496412/batang hal ini tentu berbanding terbalik dengan hasil perhitungan dengan menggunakan metode Target Profit Pricing.

Penentuan harga yang ditetapkan oleh perusahaan pada saat ini masih rendah yaitu $\mathrm{Rp}$. 16000/batang dibandingkan dengan harga yang dilakukan dengan metode Target Profit Pricing yaitu dengan harga pokok produk sebesar Rp.18,496/batang dengan asumsi keuntungan Rp.20,551/batang untuk keuntungan sebesar $10 \%, \quad$ selanjutnya Rp.21,760/batang untuk keuntungan sebesar 15\% dan Rp.23,120/batang untuk keuntungan sebesar $20 \%$.

\section{PENUTUP}

\section{Kesimpulan}

Berdasarkan hasil penelitian yang diperoleh, untuk mendapatkan titik impas (break even point) maka PT. Es Muda Perkasa harus menjual produk es 
Volume 8, Nomor 1, Februari, 2020

balok sebanyak 2400 batang es balok dengan omzet yang harus diperoleh untuk BEP adalah sebesar Rp.605,8121181818 dengan harga jual es balok sebesar Rp. 18,496412/batang.

\section{Saran}

Berikut ini merupakan saran - saran yang dapat diberikan penulis berdasarkan kesimpulan yang telah diuraikan, yaitu:

1) PT. Es Muda Perkasa sebaiknya melakukan pencatatan mengenai biaya-biaya yang dikeluarkan dalam memproduksi setiap bulannya, serta penjualan yang terjadi setiap bulannya, sehingga dapat melakukan pengklasifikasian biaya - biaya kedalam biaya tetap dan biaya variabel, untuk dapat melakukan perhitungan break even point, agar perolehan laba lebih maximal.

2) PT. Es Muda Perkasa juga sebaiknya mempertahankan dan memperbanyak produksinya karena berdasarkan analisis break even point yang telah dilakukan oleh penulis produksi es balok memiliki daya jual yang tinggi.

\section{DAFTAR PUSTAKA}

Alma. Buchari dan Ratih Hurriyati. 2008. Manajemen Corporate dan Strategi Pemasaran Jasa Pendidikan. Bandung: Alfabeta.

Damayanti. dan Christomo. 2014. Analisa Biaya Permintaan terhadap Penetapan Harga Marginal Unit Rumah di Perumahan Royal Regency. Lumajang. Jurnal Teknik Pomits. Vol 3. No 1 .

Daryanto. 2011. Manajemen Pemasaran: Sari Kuliah. Bandung: Satu Nusa
Djarwanto dan Pangestu Subagyo. 2002. Statistik Induktif. Edisi ke empat. Cetakan Keempat. BPFE. Yogyakarta.

Ferdinand. A. 2006. Metode Penelitian Manajemen. Semarang: Univ. Diponegoro.

Fransisca. Agnes. 2011. Perhitungan Harga Pokok Produksi Kain Yang Sebenarnya Untuk Penetapan Harga Jual. (Studi Kasus Pada PT. Panca Mitra Sandang Indah). Jurnal Ilmiah Akuntansi Nomor 4 Tahun ke 2.

Garrison. R. H. 2003. Managerial Acounting. Institut Teknologi Bandung. Bandung: Penerbit Erlangga.

Herjanto. Eddy. 2007. Manajemen Operasi. Edisi Ketiga. Jakarta: Grasindo

Kotler Philip. Amstrong Gary. 2013. Prinsip-Prinsip Pemasaran. Edisi Ke-12. Jakarta: PT Raja Grafindo Persada.

Kotler. a Philip. 2002. Manajemen Pemasaran. Jilid I. Edisi Indonesia. Edisi Milenium. Edisi Kesepuluh. Penerbit PT. Prenhallindo. Jakarta.

Kotler. b Philip. 2002. Manajemen Pemasaran. Jilid II. Edisi Indonesia. Edisi Milenium.Edisi Kesepuluh. Penerbit PT. Prenhallindo. Jakarta.

Kotler. Philip And Gary Armstrong. 2008. PrinsipPrinsip Pemasaran. Edisi 12. Jilid 1. Jakarta; Erlangga.

Muhammad DY. Novirani. Adianto. Penetapan Harga Jual Batu Bata Menggunakan Metode Target Profit Pricing. Jurnal Teknik Industri. Institut Teknologi Nasional (Itenas) Bandung. Vol. 02. N0. 03. 
Mulyadi. 2009. Akuntansi Biaya. Edisi 5. Yogyakarta: UPP STIM YKPN.

Sukirno. Sadono. 2012. Mikro Ekonomi Teori

Pengantar. Cetakan ke-19 dan ke-27.

Supiadi. 2014. Perlindungan Hukum Terhadap Pemenuhan Hak-Hak PDAM Kota Samarinda. Jurnal Beraja Niti. Vol 3(7): 1-23

Tjiptono. Fandy. (2011). Strategi Pemasaran. Edisi 3. Yogyakarta : ANDI 